\title{
Interference-free Determination of $\mathrm{Pb}$ in Complicated Matrices by Displacement-Cloud Point Extraction Coupled With Thermospray Flame Furnace Atomic Absorption Spectrometry
}

\author{
Wen-Ping Jia ${ }^{a *}$, Yan $\mathrm{Hu}^{\mathrm{b}}$, Fang $\mathrm{Li}^{\mathrm{a}}$, and De-Man $\mathrm{Han}^{\mathrm{a} *}$ \\ ${ }^{a}$ Department of Chemistry, Taizhou University, Jiaojiang, Zhejiang, 318000, P.R. China \\ ${ }^{b}$ Department of Materials and Environmental Protection, Chengdu Textile College \\ Chengdu 611731, P.R. China
}

\section{INTRODUCTION}

Cloud point extraction (CPE) is a green extraction protocol for the separation and preconcentration of analytes of interest from a bulk matrix $(1,2)$. The small volume of the surfactant-rich phase obtained with this methodology permits easy coupling with micro-sampling techniques such as capillary electrophoresis and electrothermal atomic absorption spectrometry (ET-AAS). Coupling of CPE with flame atomic absorption spectrometry (FAAS) has also been reported $(3,4)$, but a relatively large dilution of the surfactant-rich phase after CPE is typically required, which decreases the analyte enrichment factor. Flame furnace atomic absorption spectrometry (FF-AAS) is a great improvement for conventional FAAS, which substantially improves the sensitivity of conventional FAAS because of total sampling and prolonged residence time of the free atoms in the absorption volume (5-9). Coupling of CPE with FF-AAS is appealing because FF-AAS enables microsampling (microliter scale) and preserves the fast characteristic of conventional FAAS (10-12).

Although efficient, CPE is essentially based on the formation of hydrophobic metal-chelate complexes. Since the commonly used ligands for CPE have little selectivity towards metal ions, competition

\footnotetext{
* Corresponding autbor.

E-mail: Wen-PingJia (tzcjwp@tzc.edu.cn)

and De-Man Han (bdm@tzc.edu.cn)
}

\section{ABSTRACT}

In this study, cloud point extraction (CPE) was coupled with micro-sampling thermospray flame furnace atomic absorption spectrometry for trace lead determination. To improve the selectivity of CPE, a displacement strategy was employed based on the stability difference of metal complexes. First, $\mathrm{Zn}^{2+}$ reacts with diethyldithiocarbamate (DDTC) to form $\mathrm{Zn}$-DDTC before it is extracted; then, after removing the aqueous phase, the sample or standard solution containing $\mathrm{Pb}^{2+}$ is added and another CPE procedure is carried out. Because the stability of Pb-DDTC is larger than that of $\mathrm{Zn}-\mathrm{DDTC}, \mathrm{Pb}^{2+}$ can displace $\mathrm{Zn}^{2+}$ from the pre-extracted Zn-DDTC, and thus the preconcentration and separation of $\mathrm{Pb}^{2+}$ from the complicated sample matrix is achieved. A potential interference from co-existing transition metal ions with lower DDTC complex stability was largely eliminated since they cannot displace $\mathrm{Zn}^{2+}$ from the $\mathrm{Zn}$ DDTC complex. Compared with conventional CPE, the tolerance limit for the co-existing transition metal ions was increased by at least one order of magnitude. Under the optimal chemical and instrumental conditions, the limit of detection was $0.5 \mu \mathrm{g} / \mathrm{L}$ for lead with a sample volume of $10 \mathrm{~mL}$, and a sensitivity enhancement factor of 31 was achieved. The proposed method was successfully applied to the interferencefree determination of trace lead in tea and soil samples with a high content of co-existing heavy metals. for the complexing agent from other co-existing transition metal ions with target analytes cannot be avoided, which may cause undesirable interferences. Previously, a displacement CPE (D-CPE) was developed by Wu et al. $(13,14)$ to improve the selectivity of the CPE protocol for metal ions. The mechanism of D-CPE was similar to the displacement-sorption preconcentration strategy initially developed by Yan and co-workers (15-20). The selectivity of these preconcentration protocols has been substantially improved, which paves the way for preconcentration of trace analytes in complicated matrices.

In this work, we coupled D-CPE with FF-AAS for the interferencefree determination of $\mathrm{Pb}$ in complicated sample matrices. A universal chelating agent, DDTC, was employed for complexing of the metal ions. To achieve D-CPE, $\mathrm{Zn}^{2+}$ as the pre-extraction metal ion was complexed with DDTC and then subjected to CPE. After removal of the bulk aqueous phase, the standard or sample solution containing $\mathrm{Pb}^{2+}$ was added, and CPE was carried out for the second time. Because the stability of Pb-DDTC is greater than that of $\mathrm{Zn}-\mathrm{DDTC}, \mathrm{Pb}^{2+}$ can replace $\mathrm{Zn}^{2+}$ from the preextracted Zn-DDTC complex. Then, the obtained surfactant-rich phase (containing lead) was diluted to decrease the viscosity, directly subjected to thermospray flame furnace atomic absorption spectrometric (TS-FF-AAS) determination. Due to the displacement reaction process in the CPE procedure, the 
interferences from co-existing transition metal ions can be greatly eliminated. Considering that various nanosensors have been developed for metal ion analysis (21-23), coupling of D-CPE with various nanosensors is also expected to increase the selectivity of these nanosensors.

\section{EXPERIMENTAL}

\section{Instrumentation}

A model AAnalyst ${ }^{\mathrm{TM}} 800$ atomic absorption spectrophotometer (PerkinElmer, Inc., Shelton, CT, USA) with a deuterium background correction was used throughout this work. The working parameters (analytical line: $283.3 \mathrm{~nm}$; hollow cathode lamp current: $10.0 \mathrm{~mA}$; and spectral bandpass: $0.7 \mathrm{~nm}$ ) were employed as recommended by the manufacturer. For all experiments in this work, $8 \mathrm{~L} / \mathrm{min}$ air and $1.5 \mathrm{~L} / \mathrm{min}$ acetylene were used for the air-acetylene flame. The arrangement of TS-FF-AAS was based on previous works $(7,24$, 25). Briefly, a nickel tube (10/12 $\mathrm{mm}$ i.d./o.d. and $10 \mathrm{~cm}$ in length) was employed as the flame furnace, with six holes of $2.5 \mathrm{~mm}$ diameter at the bottom, to allow the flame gases to enter the tube. The nickel flame furnace was placed about $6 \mathrm{~mm}$ above the burner head. A ceramic capillary of $0.5 \mathrm{~mm}$ i.d./ $2.0 \mathrm{~mm}$ o.d. and 10-cm length was used for the thermospray sample introduction into the nickel tube. A peristaltic pump (HL-2D, Huxi Analytical Instrumental Co., Shanghai, P.R. China) was used to aid the sampling. Peak height absorbance was recorded for quantification. A thermostated water bath was used to maintain the desired temperature of $40{ }^{\circ} \mathrm{C}$ for the D-CPE experiments. Phase separation was achieved via a centrifuge in $10 \mathrm{~mL}$ calibrated centrifuge tubes.

\section{Reagents and Standard Solutions}

All chemicals were at least of analytical grade. Doubly deionized water was used throughout this work. Triton ${ }^{\circledR} \mathrm{X}-114$ (Fluka, Switzerland) was used as the nonionic surfactant. The complexing agent solution was prepared by dissolving DDTC (Shanghai Chemicals Co., Shanghai, P.R. China) in 1\% $\mathrm{NH}_{3} \cdot \mathrm{H}_{2} \mathrm{O}$ solution with the resultant DDTC concentration of $1 \%$ $(\mathrm{m} / \mathrm{V}) . \mathrm{Pb}^{2+}$ and $\mathrm{Zn}^{2+}$ standard stock solutions (both $100 \mu \mathrm{g} / \mathrm{mL}$ ) were purchased from the National Research Center for Standard Materials (NRCSM) of China. The working solutions were prepared by serial dilution of the standard stock solutions prior to use.

\section{Samples and Sample Pretreatment}

To validate the accuracy of the developed method, several certified reference materials (CRMs) were purchased from NRCSM: GBW 07605 Tea; GBW 07601 and GBW 09101 Human Hair; GBW 07401 and GBW 07402 Soil; and GBW 07309 Marine Sediment. The samples were digested with $10 \mathrm{~mL}$ of $1+1 \mathrm{HNO}_{3}$ and several drops of $\mathrm{HClO}_{4}$. After the acids were evaporated, the moist residue was dissolved in diluted $\mathrm{HNO}_{3}(0.001 \mathrm{M})$ and transferred into volumetric flasks. The tea and human hair samples were subjected to D-CPE directly. The analyte solutions of soil and sediments were left standing for 30 minutes before D-CPE.

\section{Operating Procedure}

The operating procedure of the D-CPE is illustrated in Figure 1 (a and $b$ ) and the schematic. For preextraction of $\mathrm{Zn}^{2+}$, aliquots of 10 $\mathrm{mL}$ solution in $10 \mathrm{~mL}$ centrifuge tubes, containing $\mathrm{Zn}^{2+}(40 \mu \mathrm{g} / \mathrm{mL})$, DDTC $(0.02 \%, \mathrm{~m} / \mathrm{V})$, and Triton ${ }^{\circledR}$ $\mathrm{X}-114(0.2 \%, \mathrm{~m} / \mathrm{V}$, equivalent to $200 \mu \mathrm{L}$ Triton $\mathrm{X}-114$ in the $10 \mathrm{~mL}$

\section{Atomic}

mixed solution) were heated in the thermostated water bath at $40{ }^{\circ} \mathrm{C}$ for 10 minutes. After heating, the resultant solution was subjected to centrifugation at $4000 \mathrm{rpm}$ for 5 minutes for phase separation. The supernatant was carefully removed with a syringe and the final volume of the surfactant-rich phase containing Zn-DDTC complex and Triton $\mathrm{X}-114$ was used for the extraction of $\mathrm{Pb}^{2+}$. For the subsequent displacement extraction, sample or standard solutions containing $\mathrm{Pb}^{2+}$ were added to the centrifuge tubes and shaken to dissolve the surfactant-rich phase. Then, the centrifuge tubes were subjected to another heating process for the extraction of $\mathrm{Zn}^{2+}$. After removing the bulk aqueous phase, the resultant surfactant-rich phase was diluted with a solution containing $10 \% \mathrm{HNO}_{3}(\mathrm{v} / \mathrm{v})$ and $20 \%$ methanol (v/v) to $600 \mu \mathrm{L}$ for TS-FF-AAS measurement.

\section{RESULTS AND DISCUSSION}

\section{Pre-extraction Conditions}

For CPE, the extraction efficiency depends on the hydrophobicity of the ligands and the complexes, the apparent equilibrium constants in the micellar medium, the kinetics of the complex formation, and the transfer between the phases. In this work, the displacement reaction between $\mathrm{Pb}^{2+}$ and $\mathrm{Zn}-\mathrm{DDTC}$ should be considered the first step. The effect of the pre-extraction solution acidity (in terms of the acid concentration of the zinc solution) on the analyte signal was investigated in the $\mathrm{pH}$ range of 3.5-10 with a DDTC concentration of $0.02 \%(\mathrm{~m} / \mathrm{V})$ and a surfactant concentration of $0.2 \%$ $(\mathrm{m} / \mathrm{V})$. As shown in Figure 1A, the optimum $\mathrm{pH}$ of the $\mathrm{Zn}^{2+}$ solution lies in the 3.5-8.5 range, and a final $\mathrm{pH}$ of 5 for $\mathrm{Zn}^{2+}$ was selected for the pre-extraction. A decrease in the extraction efficiency was observed when the $\mathrm{pH}$ was lower 


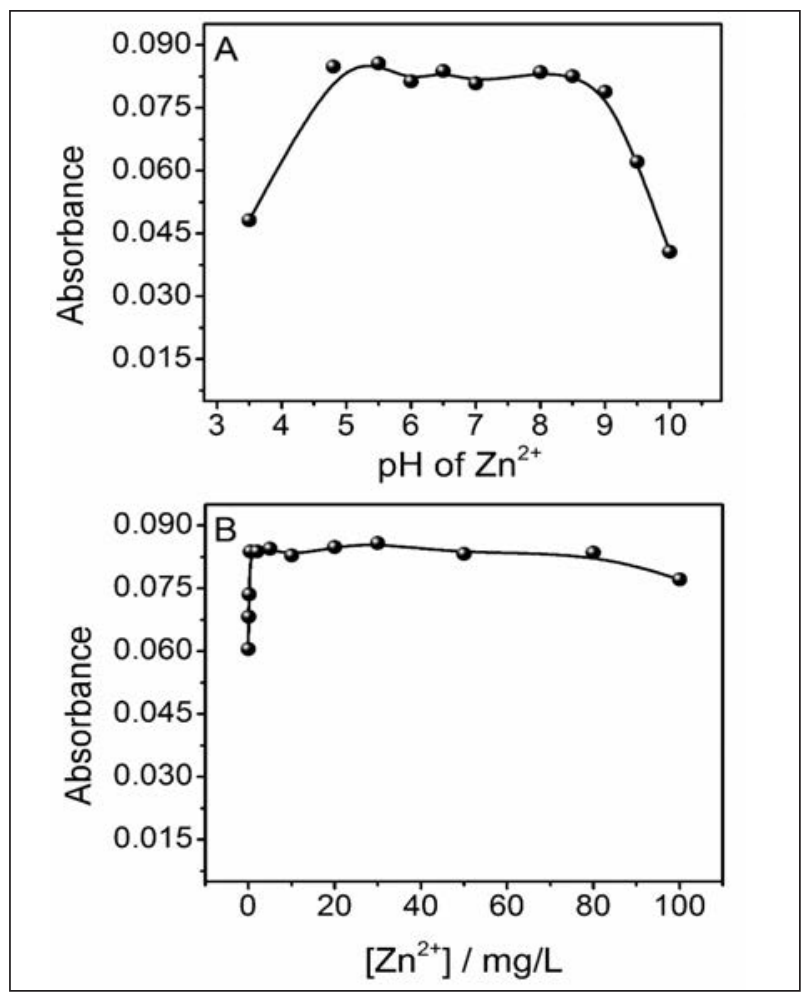

Fig. 1. Influence of pre-extraction conditions on the D-CPE of $\mathrm{Pb}(20 \mu \mathrm{g} / \mathrm{L})$ : (A) $\mathrm{pH}$ of $\mathrm{Zn}$ solution, (B) concentration of $\mathrm{Zn}$ solution. Other experimental conditions: $p H$ of sample solution, 3.5; DDTC: $0.02 \%(\mathrm{~m} / \mathrm{V})$; Triton $X-114: 0.2 \%(\mathrm{~m} / \mathrm{v})$.

than 3, probably because dithiocarbamic acid can be hydrolyzed with the liberation of $\mathrm{CS}_{2}$ and a consequent loss of complexing activity. For a $\mathrm{pH}$ higher than 8.5 , less efficient complexing of $\mathrm{Zn}^{2+}$ with DDTC may be encountered.

The concentration of $\mathrm{Zn}^{2+}$ had a pronounced effect on the amount of pre-extracted Zn-DDTC, and thus for the subsequent displacement extraction. Figure 1B shows the dependence of the analytical signal on the $\mathrm{Zn}^{2+}$ concentration, which indicates that the optimum concentrations of $\mathrm{Zn}^{2+}$ were higher than $2 \mathrm{mg} / \mathrm{L}$. Control experiments showed that the extracted $\mathrm{Zn}^{2+}$ species was indeed Zn-DDTC (with FAAS analysis of the supernatant solution after the first extraction). After the second extraction process, the average concentrations of the supernatant $\mathrm{Zn}$ after displacement

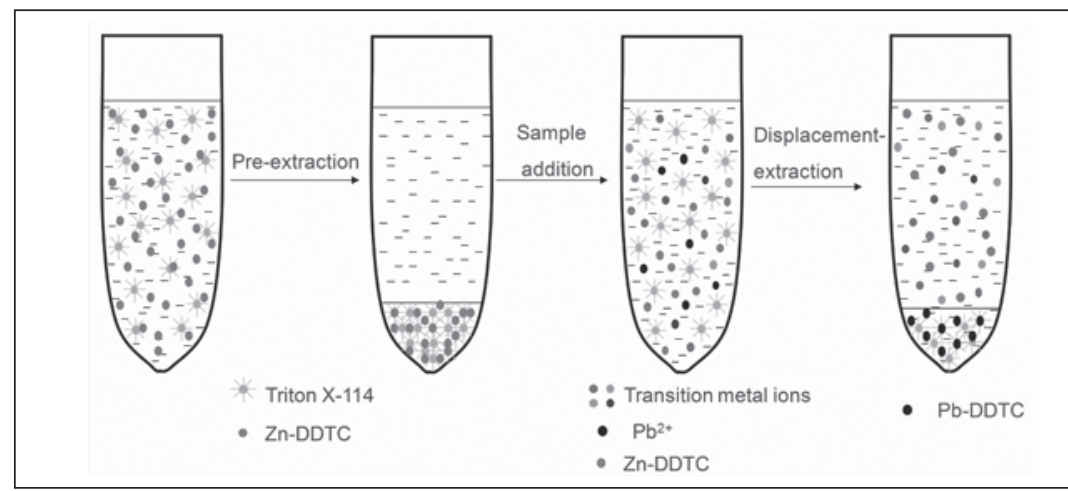

Schematic of operating procedure of D-CPE for preconcentration of $\mathrm{Pb}$.

pre-extraction, and the subsequent displacement between $\mathrm{Pb}^{2+}$ and $\mathrm{Zn}$ DDTC. The analytical signal as a function of the DDTC concentration in the range of $0-0.05 \%(\mathrm{~m} / \mathrm{V})$ is shown in Figure 2B. Stable atomic absorbance for lead was obtained in the presence of $0.01-0.05 \%$ DDTC. In order to minimize the background caused by DDTC (a sodium salt) and achieve efficient preconcentration, a DDTC concentration of $0.02 \%$ $(\mathrm{m} / \mathrm{V})$ was selected for this work.

Triton ${ }^{\circledR} \mathrm{X}-114$ has a lower cloud point temperature (about $30^{\circ} \mathrm{C}$ ) than other surfactants, which is appropriate for the extraction. The amount of the non-ionic surfactant affects not only the extraction efficiency but also the volume of the surfactant-rich phase. Figure 2C highlights the Triton $\mathrm{X}-114$ concentration on the $\mathrm{D}-\mathrm{CPE}$ of $\mathrm{Pb}^{2+}$. The atomic absorbance of lead increased as the Triton $\mathrm{X}-114$ concentration increased from 0 to $0.2 \%(\mathrm{~m} / \mathrm{v})$, then leveled off in both cases. To fulfill the "environmentally benign" extraction, a low concentration of Triton X-114, 0.2\% (m/v), was employed for the rest of this work.

\section{Interference Evaluation}

Due to the introduction of a displacement reaction, the selectivity of previously developed preconcentration protocols was largely improved, and the same effect was also expected in the current work. 


\section{Atomic Apectroscopy \\ $\bigcup$ Vol. 36(2), March/April 2015}

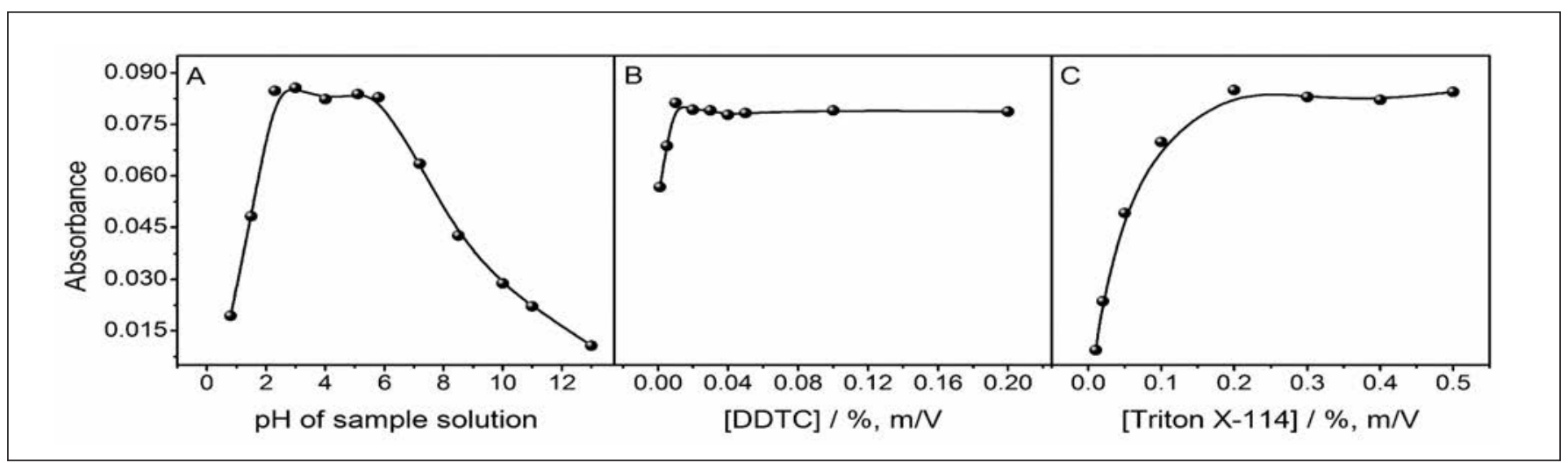

Fig. 2. (A) Influence of sample solution $\mathrm{pH}$, (B) DDTC concentration, and (C) Triton X-114 concentration on the D-CPE of Pb $(20 \mu \mathrm{g} / \mathrm{L})$. Other experimental conditions: $30 \mathrm{mg} / \mathrm{L}$ of $\mathrm{Zn}$ solution and $\mathrm{pH} 5$.

The effects of several potentially interfering species (all in the form of nitrate) were carefully studied, and the results are listed in Table I. In order to fully demonstrate the high selectivity resulting from the displacement reaction, the recoveries of $20 \mu \mathrm{g} / \mathrm{L} \mathrm{Pb}^{2+}$ in the presence of the same interfering species under conventional CPE were investigated, and the results are also tabulated in Table I. The tolerance limit for co-existing transition metal ions for the current displacement-CPE system was improved by over two orders of magnitude, in comparison with conventional CPE extraction. As expected, metals with lower stability than that of $\mathrm{Zn}$ DDTC (Fe and Mn, the most abundant transition metals in soil and ore samples) cannot displace $\mathrm{Zn}^{2+}$ from Zn-DDTC and thus causes no interference for $\mathrm{Pb}^{2+}$ extraction and its later determination. For Co, $\mathrm{Cd}$, and $\mathrm{Zn}$ (whose stability are between those of Pb-DDTC and ZnDDTC), although they can displace $\mathrm{Zn}^{2+}$ from the $\mathrm{Zn}$-DDTC complex, the stability of Pb-DDTC is still higher. Accordingly, they also did not interfere with $\mathrm{Pb}$ detection. However, for $\mathrm{Cu}^{2+}$ and $\mathrm{Ni}^{2+}$, since their DDTC complexes have a higher stability over Pb-DDTC, adverse effects were observed. In addition, the interfering effects of macro constituents $\left(\mathrm{K}^{+}, \mathrm{Na}^{+}, \mathrm{Ca}^{2+}\right.$,
TABLE I

Comparison of Interference From Co-exiting Transitional Metal Ions for the Determination of $20 \mu \mathrm{g} / \mathrm{L} \mathrm{Pb}^{2+}$ by Conventional CPE Preconcentration and the Present Displacement-CPE Preconcentration

\begin{tabular}{|c|c|c|c|}
\hline \multirow[t]{2}{*}{ Ion } & \multirow{2}{*}{$\begin{array}{c}\text { Concentration } \\
(\mu \mathrm{g} / \mathrm{mL})\end{array}$} & \multicolumn{2}{|c|}{ Recovery (\%) } \\
\hline & & Displacement-CPE & Conventional CPE \\
\hline \multirow[t]{3}{*}{ Cd(II) } & 5 & - & 71 \\
\hline & 20 & 97 & - \\
\hline & 100 & 84 & - \\
\hline \multirow[t]{3}{*}{$\mathrm{Fe}(\mathrm{III})$} & 10 & - & 59 \\
\hline & 100 & 98 & - \\
\hline & 500 & 92 & - \\
\hline \multirow[t]{3}{*}{$\mathrm{Co}(\mathrm{II})$} & 10 & - & 64 \\
\hline & 50 & 99 & - \\
\hline & 200 & 95 & - \\
\hline \multirow[t]{3}{*}{$\mathrm{Zn}(\mathrm{II})$} & 10 & - & 79 \\
\hline & 100 & 99 & - \\
\hline & 1000 & 95 & - \\
\hline \multirow[t]{3}{*}{$\operatorname{Mn}(\mathrm{II})$} & 10 & - & 88 \\
\hline & 100 & 107 & - \\
\hline & 1000 & 101 & - \\
\hline $\mathrm{Ni}(\mathrm{II})$ & 10 & 80 & 84 \\
\hline $\mathrm{Cu}(\mathrm{II})$ & 10 & 75 & 87 \\
\hline K & 2000 & 104 & - \\
\hline $\mathrm{Na}$ & 2000 & 106 & - \\
\hline $\mathrm{Ca}$ & 2000 & 103 & - \\
\hline $\mathrm{Mg}$ & 2000 & 98 & - \\
\hline $\mathrm{Al}$ & 2000 & 97 & - \\
\hline
\end{tabular}


$\mathrm{Mg}^{2+}$, and $\mathrm{Al}^{3+}$ ) in common samples were also studied for the D-CPE. Because they cannot chelate with DDTC or displace $\mathrm{Zn}^{2+}$ from $\mathrm{Zn}$ DDTC, no interference was observed even at a concentration level as high as $2000 \mu \mathrm{g} / \mathrm{mL}$.

\section{Analytical Characteristics}

The analytical characteristic data for the proposed D-CPE TS-FF-AAS were evaluated and are summarized. The sensitivity enhancement factor was found to be 31 , which is defined as the slope ratio of the calibration curves for the determination of lead by D-CPE TS-FF-AAS (Figure 3A) and conventional TS-FFAAS (Figure 3B), respectively. The precision (RSD) for 8 replicate measurements of $20 \mu \mathrm{g} \mathrm{L}^{-1}$ of lead standard solution was $4.5 \%$. The limit of detection (LOD, $3 \sigma$ ) for the determination of lead was found to be $0.5 \mu \mathrm{g} / \mathrm{L}$, and the upper linear dynamic range of $160 \mu \mathrm{g} / \mathrm{L}$. Considering that the lead content in typical soil or biological samples is at the $\mu \mathrm{g} / \mathrm{g}$ level, the proposed method is suitable for environmental and biological monitoring applications.

To evaluate the accuracy of the proposed method, several CRMs (tea, human hair, soil, and marine sediment) were analyzed for lead and the results are given in Table II. A student's $t$-test shows that the analytical results by the proposed method show no significant difference from the certified values at the confidence level of $95 \%$. Despite the complicated matrices (botanical, biological, and environmental matrices), the current method still showed very high selectivity for the accurate quantification of trace lead in these samples.

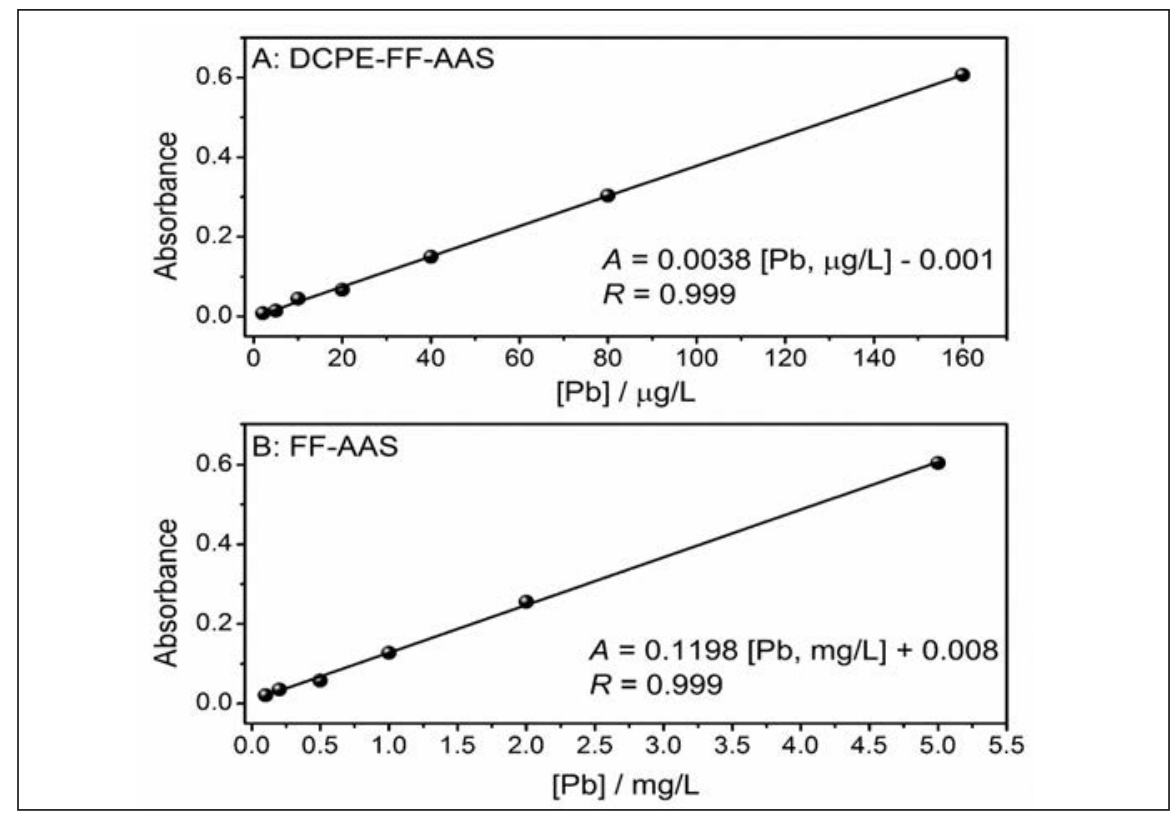

Fig. 3. Calibration curves for lead by D-CPE TS-FF-AAS (A) and TS-FF-AAS (B).

TABLE II

Analytical Results for the Determination of Trace Pb in CRMs ( $\mu \mathrm{g} / \mathrm{g})$

\begin{tabular}{lcc}
\hline CRM & Certified $(\mu \mathrm{g} / \mathrm{g})$ & Found $(\mu \mathrm{g} / \mathrm{g})^{\mathrm{a}}$ \\
\hline GBW 07605 tea & $4.4 \pm 0.3$ & $4.0 \pm 0.5$ \\
GBW 07601 human hair & $8.8 \pm 1.1$ & $8.6 \pm 0.7$ \\
GBW 09101 human hair & $7.2 \pm 0.7$ & $7.5 \pm 0.8$ \\
GBW 07401 soil & $98 \pm 8$ & $94 \pm 6$ \\
GBW 07402 soil & $20 \pm 4$ & $22 \pm 5$ \\
GBW 07309 marine sediment & $23 \pm 4$ & $20 \pm 4$ \\
\hline
\end{tabular}

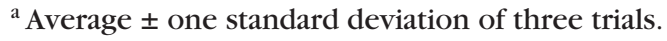

\section{CONCLUSION}

In summary, a displacementcloud point extraction (D-CPE) technique was proposed for the selective extraction of trace lead from complicated matrices. The most favorable feature of this approach is its much higher selectivity over a conventional CPE procedure. Obviously, the displacement-CPE principle can be employed to other chelating reagent systems, such as APDC, dithiozone, etc., for the selective quantification of other trace elements in complicated matrices. Even though various nanosensors have been developed for metal ion analysis, but seldom for complicated matrices. The marriage of D-CPE with various nanosensors may also effectively eliminate interferences and increase the selectivity of these nanosensors, thus paving the way for further applications of these nanosensors in real sample matrices. 


\section{ACKNOWLEDGMENT}

We acknowledge the financial support for this project from the Youth Foundation of Chengdu Textile College (2012fz1kB07), the Education Department of Sichuan Province (14ZB0326), the Science and Technology Plan Project of Zhejiang Province (2013C37052), and the Natural Science Foundation of China (21375092), as well as the State Key Laboratory of Chemical Resources Engineering (CRE-2012C-303).

$\overline{\text { Received March 22, } 2014 .}$

\section{REFERENCES}

1. C.B. Ojeda and F.S. Rojas, Anal. Bioanal. Chem. 394, 759 (2009).

2. K. Pytlakowska, V. Kozik, and M. Dabioch, Talanta 110, 202 (2013).

3. S.G. Silva, P.V. Oliveira, J.A. Nobrega, and F.R.P. Rocha, Anal. Methods 1, 68 (2009).

4. H.I. Ulusoy, R. Gurkan, U. Aksoy, and M. Akcay, Microchem J. 99, 76 (2011).

5. P. Wu, S.P. He, B. Luo, and X.D. Hou, Appl. Spectrosc. Rev. 44, 411 (2009).

6. M.A. Bezerra, V.A. Lemos, J.S. Garcia, D.G. da Silva, A.S. Araújo, and M.A.Z. Arruda, Talanta 82, 437 (2010).

7. P. Wu, R. Liu, H. Berndt, Y. Lv, and X.D. Hou, J. Anal. At. Spectrom. 23, 37 (2008).

8. A. Gáspár and H. Berndt, Anal. Chem. 72, 240 (2000).

9. P. Wu, Y.C. Zhang, R. Liu, Y. Lv, and X.D. Hou, Talanta 77, 1778 (2009).

10. P. Wu, Y.C. Zhang, Y. Lv, and X.D. Hou, Spectrochim. Acta Part B 61, 1310 (2006).

11. G.L. Donati, C.C. Nascentes, A.R.A. Nogueira, M.A.Z. Arruda, and J.A. Nóbrega, Microchem. J. 82, 189 (2006)

12. L.M. Coelho, M.A. Bezerra, M.A.Z. Arruda, R.E. Bruns, and S.L.C. Ferreira, Sep. Sci. Technol. 43, 815 (2008).

13. P. Wu, Y. Gao, G.L. Cheng, W.S Yang, Y. Lv, and X.D. Hou, J. Anal. At. Spectrom. 23, 752 (2008).

14. Y. Gao, P. Wu, W. Li, Y.L. Xuan, and X.D. Hou, Talanta 81, 586 (2010)

15. Y. Li, Y. Jiang, X.P. Yan, and Z.M. Ni, Environ. Sci. Technol. 36, 4886 (2002).

16. X.P. Yan, Y. Li, and Y. Jiang, J. Anal. At. Spectrom. 17, 610 (2002).

17. X.P. Yan, Y. Li, and Y. Jiang, Anal. Chem. 75, 2251 (2003).

18. W.P. Jia, D.M. Han, T. Gao, and F. Li, Atom. Spectrosc. 30, 201 (2009).

\section{A Spmic $_{\text {Vol. } 362(2) \text { March }}^{\text {topril } 2015}$}

19. P. Liang, E.J. Yang, and L.J. Wen, Anal. Methods 5, 4419 (2013).

20. P. Wu, C.Y. Xu, and X.D. Hou, Appl. Spectrosc. Rev. 48, 629 (2013).

21. P. Wu, T. Zhao, S.L. Wang, and X.D. Hou, Nanoscale 6, 43 (2014).

22. D.J. de Aberasturi, J.M. Montenegro, I.R. de Larramendi, T. Rojo, T.A. Klar, R. Alvarez-Puebla, L.M. Liz-Marzán, and W.J. Parak, Chem. Mater. 24, 738 (2012).

23. P. Wu and X.-P. Yan, Chem. Soc. Rev. 42, 5489 (2013)

24. C.J. Zeng, F.W. Yang, J. Zhou, and H.L. Qiu, Spectrosc. Lett. 44, 278 (2011).

25. X.D. Wen, Y. Zhao, Q.W. Deng, J. Guo, X. Zhao, and S.L. Ji, Microchim. Acta 178, 139 (2012). 